\title{
Robotic-assisted approach for complex inguinal hernias
}

\author{
Flavio Malcher ${ }^{1}$, Diego L. Lima1, Raquel N. Cordeiro L. Lima², Prashanth Sreeramoju ${ }^{1}$ \\ 'Department of Surgery, Montefiore Medical Center, The Bronx, New York, NY 10461, USA. \\ ${ }^{2}$ Department of Surgery, Pernambuco Health College, Recife 51150-000, Brazil.
}

Correspondence to: Dr. Flavio Malcher, Department of Surgery, Montefiore Medical Center, 1825 Eastchester Rd, The Bronx, New York, NY 10461, USA. E-mail: fmalcher@montefiore.org

How to cite this article: Malcher F, Lima DL, Lima RNCL, Sreeramoju P. Robotic-assisted approach for complex inguinal hernias. Mini-invasive Surg 2021;5:31. https://dx.doi.org/10.20517/2574-1225.2021.48

Received: 2 Apr 2021 First Decision: 20 Apr 2021 Revised: 28 Apr 2021 Accepted: 7 May 2021 First online: 15 Jun 2021

Academic Editor: William W. Hope Copy Editor: Xi-Jun Chen Production Editor: Xi-Jun Chen

\begin{abstract}
Laparoscopic inguinal hernia repair was introduced in the early nineties as a minimally invasive alternative to the classic Lichtenstein repair. Over the decades, minimally invasive approaches have demonstrated both postoperative benefits and easy replicability. Robotic inguinal hernia repair has been shown as a safe alternative to laparoscopic repair. Furthermore, due to technical difficulties, complex inguinal hernia repairs (scrotal hernias, incarcerated hernias, recurrent hernias, mesh removal, and previous pelvic surgery) are a relative contraindication for laparoscopic repairs. In this article, we highlight the advantages of the robotic approach for complex cases of inguinal hernia.
\end{abstract}

Keywords: Robotic surgery, inguinal hernia, abdominal wall, minimally invasive surgical procedures

\section{INTRODUCTION}

Laparoscopic inguinal hernia repair was introduced in the early nineties as a minimally invasive alternative to the classic Lichtenstein repair ${ }^{[1]}$. Over the next decades, two different minimally invasive approaches have been extensively published: totally extraperitoneal repair (TEP) and transabdominal preperitoneal repair (TAPP), demonstrating both postoperative benefits and easy replicability ${ }^{[2-4]}$. Recently, minimally invasive surgery (MIS) has become the gold standard approach for bilateral inguinal hernia repair and has also been suggested for primary and recurrent unilateral inguinal hernias when expertise is present ${ }^{[5]}$. With the 
advancing technology and progressing MIS, surgeons are utilizing robotic platforms to perform minimally invasive hernia repairs following the same technical principles. This approach has been changing surgeons' and patients' experiences.

Robotic inguinal hernia repair has been shown as a safe alternative to laparoscopic repair by studies from Kudsi et al. ${ }^{[6]}$, Escobar Dominguez et al. ${ }^{\left[{ }^{[]]}\right.}$, and Tam et al. ${ }^{[8]}$. The robotic approach follows the same technical principles of the laparoscopic TAPP approach. Literature review of robotic inguinal hernia repair (rIHR) is composed of many retrospective and single-institution studies with few Randomized Controlled trials and meta-analysis. A meta-analysis performed by Aiolfi et al. ${ }^{[9]}$ showed no differences in term of postoperative outcomes and complications between laparoscopic and robotic approaches in the short term. A national database review found that robotic repairs showed a lower overall complication rate when compared with open or laparoscopic approaches ${ }^{[10]}$.

The Robotic Inguinal $v s$. Transabdominal Laparoscopic Inguinal Hernia Repair (RIVAL) trial demonstrated no added benefit for robotic surgery compared to laparoscopic surgery for unilateral primary or recurrent hernia repairs; however, they have also concluded robotic surgery plays a role in specific settings ${ }^{[11]}$. Furthermore, due to technical difficulties, complex inguinal hernia repairs (scrotal hernias, incarcerated hernias, recurrent hernias, mesh removal, and previous pelvic surgery) are a relative contraindication for laparoscopic repairs ${ }^{[6]}$. In this article, we highlight the advantages of the robotic approach for complex cases of inguinal hernia.

\section{The road map for safety in MIS hernia repair}

The evolution of MIS inguinal hernia repair has mirrored the evolution of laparoscopic cholecystectomy. Surgeons have developed an analogous idea of safety for MIS inguinal hernia repair ${ }^{[4,12-14]}$. This concept has created a road map to maintain a safe and efficient laparoscopic approach for inguinal hernia repair. As more and more surgeons perform MIS repair for inguinal hernias, this road map is conceptualized to provide a standard dissection and posterior repair.

Furthermore, the posterior anatomical view of the groin might be challenging even for experienced surgeons. Furtado et al. ${ }^{[15]}$ has developed a concept to understand the groin's posterior anatomy by identifying anatomical landmarks and important triangular areas to avoid injury of noble structures. The combination of the stepwise critical view of safety with the identification of anatomical landmarks has created a safe alternative for surgeons worldwide to perform an effective MIS inguinal hernia repair. Claus et al. ${ }^{[4]}$ have condensed this road map in the 10 golden rules for a safe MIS inguinal hernia repair that can be easily adapted for the robotic approach [Table 1].

\section{Robotic inguinal hernia repair after prostatectomy}

The most common complications after radical prostatectomy are impotence and urinary incontinence ${ }^{[16]}$. Inguinal hernia is another common complication confirmed by several studies ${ }^{[17-20]}$. A meta-analysis published by Alder et al. ${ }^{[16]}$ has shown a high incidence of inguinal hernia after open radical prostatectomy followed by laparoscopic and robotic prostatectomies. There was no difference between both MIS repairs ${ }^{[16]}$.

Different studies have been published showing the feasibility of performing rIHR concomitant to radical prostatectomies $^{[21,22]}$. Clinically, non-diagnosed inguinal hernias before the surgical procedure are found in $20 \%$ to $33 \%$ of robotic prostatectomies ${ }^{[23]}$. There is a lack of data regarding the recommended approach for inguinal hernia repair after prostatectomies. Furthermore, the HerniaSurge guidelines recommended surgeons to consider an anterior approach when performing hernia repair in patients with prior urologic 
Step 1: Pre-peritoneal access: high flap on TAPP vs direct access in TEP

Step 2: Peritoneal plane to protect retroperitoneal nerves

Step 3: Medial dissection should reach the midline and dive into Retzius

Step 4: Femoral hernia needs to be excluded by visualization of femoral orifice

Step 5: Posterior dissection of peritoneum until psoas muscles and iliac vessels to parietalize the elements of the cord

Step 6: Large and long indirect sacs may be transected to minimize trauma to elements of the cord

Step 7: Active exploration of the deep inguinal ring should be done to exclude and/or reduce cord lipomas

Step 8: Minimal 3-4 cm overlap of all defects should be granted with a mesh with the minimum size of $15 \mathrm{~cm} \times 10 \mathrm{~cm}$

Step 9: Most of cases do not need traumatic fixation

Step 10: Final step of preperitoneal deflation on TEP or peritoneal closure on TAPP should ensure no mesh displacement

MIS: Minimally invasive surgery; TEP: totally extraperitoneal repair; TAPP: transabdominal preperitoneal repair.

pelvic operations in their 2018 guidelines ${ }^{[5]}$. The scar tissue formed after the pelvic operation may turn the inguinal repair more challenging with further complications. The scarred tissue planes can limit the ability to do a proper medial dissection and lead to a bladder injury or a major vascular injury over the iliac vessels after lymph node dissection is performed during the radical prostatectomy. The robotic approach may bring some advantages to otherwise a more challenging repair by MIS technique. Surgeons working with instruments with improved dexterity and a high-definition 3D vision may allow performing a successful procedure with low complication rates.

Despite the HerniaSurge guidelines, many studies have been published showing the laparoscopic approach for inguinal hernias after prostatectomies ${ }^{[24-28]}$. There are two studies in the literature regarding robotic inguinal hernia repair after urologic procedures to our knowledge. Angus et al. ${ }^{[29]}$, using the Americas Hernia Society Quality Collaborative (AHSQC) database developed by the Americas Hernia Society, identified 65 male patients submitted to rIHR after a prostatectomy. Performing a propensity match score with 3:1 patients submitted to a robotic repair, the group with previous urologic surgery had no difference compared to the control group in intra-operative and post-operative complications, 30-day recurrence, and re-admissions of surgical site outcomes. As this is certainly an encouraging result with a limitation of the retrospective design of the study. Dewulf et al. ${ }^{[30]}$ published their experience with a cohort of 22 patients submitted to robotic inguinal repair after prostatectomy. There were no intraoperative complications, no conversions to open or laparoscopic surgery and at 4 weeks of follow-up, $22.7 \%$ had an asymptomatic seroma ${ }^{[30]}$. Also, more studies and trials are needed to demonstrate the robotic approach's safety and feasibility in these challenging cases.

Surgeons may be navigating in unknown waters during these procedures. Fibrosis from the previous lymph node dissection may alter the anatomy on top of the external iliac vessels, and extra attention is necessary for avoiding a major vascular injury. The bladder dissection is more difficult and the filling of it with saline may help to identify the proper plane. Any injury should be recognized and promptly repaired. A leak test may be performed with dye after the dissection to rule out any missed bladder injury. The enhanced 3D vision of the robotic platform with a scaling of movements, associated with the increased dexterity of the surgical instruments with tremor filtering, may be beneficial in identifying structures and avoiding those major injuries.

In our academic center, the tips and tricks described above were essential to performing a safe robotic inguinal repair in 11 patients who were previously submitted to a prostatectomy, without major intraoperative or postoperative complications. 


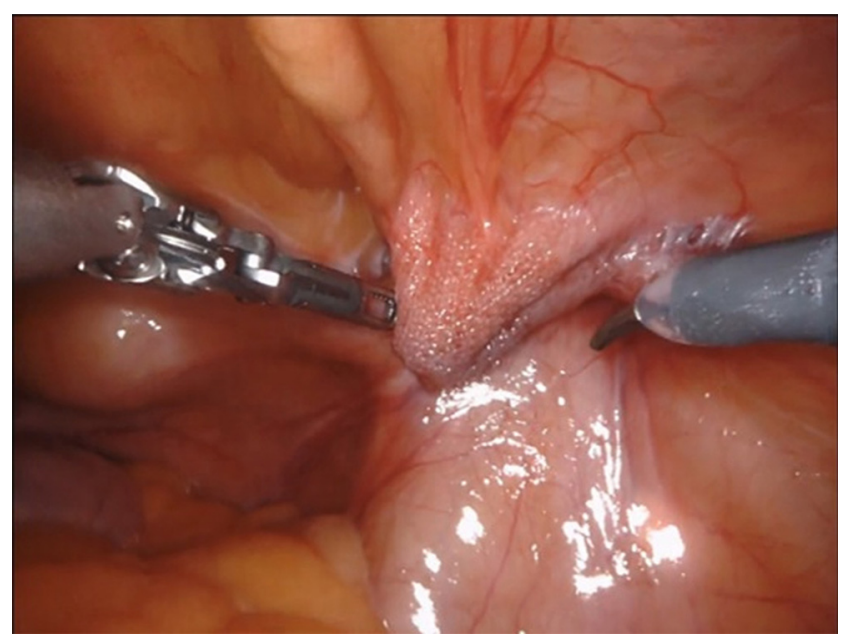

Figure 1. Identification of right-side inguinal plug before robotic mesh explantation.

\section{Robotic mesh explantation}

Most hernia repairs in the United States are performed with $\operatorname{mesh}^{[31]}$. As more meshes are implanted, more may need to be removed due to complications ${ }^{[32]}$.

Mesh infection, mesh-related pain, meshoma, recurrence, chronic pain, and entrapment of the nerve are reported as the main indications for mesh removal ${ }^{[33-35]}$.

Studies have shown that chronic pain rates after MIS inguinal repair are lower than those after open inguinal repairs ${ }^{[3,37]}$. The main advantage of endoscopic repair on reducing chronic pain is avoiding nerve dissection for mesh implantation and avoiding traumatic fixation.

There are different options to manage patients with chronic pain after inguinal hernia repair. In certain situations, removing the mesh (mostly plugs) is necessary for addressing the problem [Figure 1]. Open mesh removal is an established technique, but scarred tissue from the previous repair may alter the anatomy, and injury to the critical structures may happen. Laparoscopic mesh removal may be incredibly challenging due to the innate nature of straight instruments and 2-dimensional vision.

One possibility is to use the robotic platform. Truong et al. ${ }^{[35]}$ have described a step-by-step guide for removing the pre-peritoneal mesh using the robotic platform. The robotic mesh explantation (RoME) is feasible due to the same advantages as discussed for inguinal repairs after prostatectomies. It may be less challenging to work on the scarred tissue using robotic articulated instruments than using classic laparoscopic instruments.

Two concepts are essential for operating in the inflamed and fibrotic areas. The first one is starting the dissection over virgin planes facilitates access to the area where the mesh is scarred to vital structures. The second one is to dissect on and at the mesh while trying to free the mesh from the surrounding adhered structures. The aim of mesh explantation is to decrease the burden of foreign body material as much as possible without compromising vital structures. It is considered an acceptable practice to leave a small piece of the foreign body material behind. A negative margin is not necessary as in oncologic procedures. In inguinal mesh removal, the nerves are usually involved, and neurectomies are often necessary. 


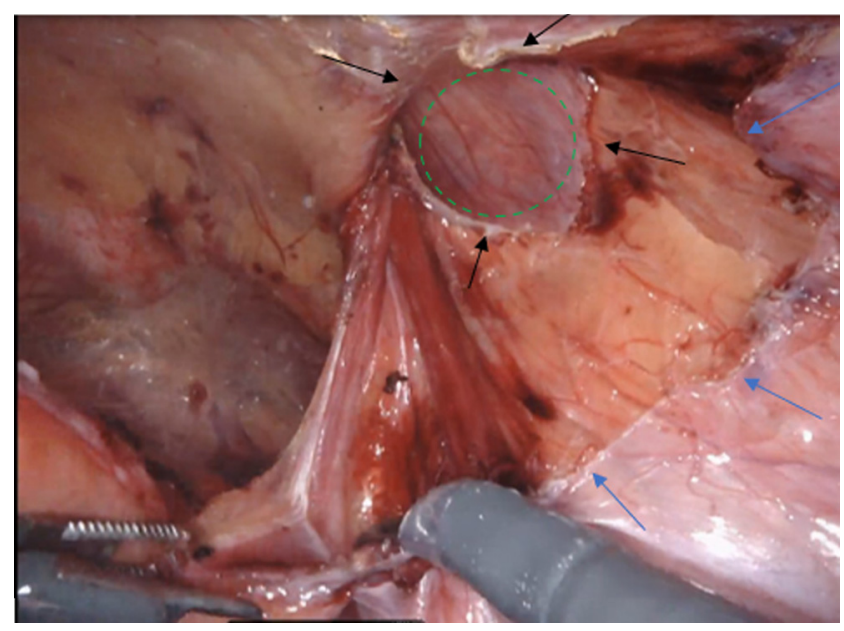

Figure 2. Right side inguinoscrotal hernia. Green circle shows large indirect inguinal hernia defect. Black arrows show distal edge of the indirect hernia sac after transection and blue arrows show proximal edge of the transected sac.

Our initial experience of 10 inguinal RoME proved to be safe with no major complications, once executed by an experienced surgeon.

A preoperative pain mapping is crucial for evaluating these patients to determine which nerves are affected. The genitofemoral and lateral-cutaneous nerves are the most common nerves involved during MIS inguinal hernia repair. Furthermore, orchiectomy may be necessary, and all these complications should be discussed with the patients and addressed in the consent. The robotic platform may be the best option to navigate through these challenging situations with minimal damage.

\section{Robotic inguinal repair in inguinoscrotal hernias}

Inguinoscrotal hernias represent a challenge for minimally invasive surgeons, and its management is still debatable ${ }^{[38]}$. Early reports on laparoscopic TAPP repair of inguinoscrotal hernias and guidelines of endoscopic repair of scrotal hernias validated the MIS approach ${ }^{[3,40]}$. However, there is no consensus on the best surgical approach.

Despite many reports in the literature regarding robotic TAPP for inguinal hernia repairs, there is a paucity of studies regarding inguinoscrotal hernias ${ }^{[41]}$. Yheulon et al. ${ }^{[41]}$ demonstrated rIHR in 14 patients with inguinoscrotal hernias with no major complications. Seroma was the most common complication. These cases may be more challenging using regular laparoscopic instruments and the robotic platform, with the articulated instruments, enhanced visualization and the ability to control a fourth arm, may allow the surgeon to perform these complex cases with few post-operative complications.

Morrell et al. ${ }^{[38]}$ demonstrated a laparoscopic technique showing a special technique for those complex inguinoscrotal hernias. The primary abandon-the-sac technique performed in 26 patients was based on an incomplete dissection of the distal sac, leaving it into the inguinal canal and scrotum [Figure 2]. This technique can be safely used in patients with inguinoscrotal hernias. Seroma seems to be its main complication, but it avoids hematomas and possible ischemic orchitis from extensive dissection of the cord structures. Siow et al. ${ }^{[42]}$ demonstrated a modified laparoscopic TAPP technique for incarcerated scrotal hernias with a scrotal incision in 20 patients. This modification has facilitated performing an MIS repair for large and complex inguinoscrotal hernias, which would otherwise be managed by an open technique. 


\section{CONCLUSION}

Management of complex inguinal hernias is challenging. Adequate surgical knowledge and mastery of inguinal anatomy are essential for the surgical technique's success. The robotic platform would enable us to perform otherwise a technically challenging MIS procedure safely. Robotic surgery is still in the early phase of adoption for inguinal hernia repairs. More well-designed studies are needed to evaluate its efficacy in groin hernia repairs.

\section{DECLARATIONS}

\section{Authors' contributions}

Manuscript preparation and editing: Lima DL, Lima RNCL, Sreeramoju P, Malcher F

Study design: Malcher F, Lima RNCL, Lima DL, Sreeramoju P

\section{Availability of data and materials}

Not applicable.

\section{Financial support and sponsorship}

None.

\section{Conflicts of interest}

Dr. Lima DL, Lima RNCL, Sreeramoju P disclose no financial relationships with industry or conflicts of interest.

Dr. Malcher F discloses consulting fees from BD \& Medtronic, outside the submitted work.

\section{Ethical approval and consent to participate}

Not applicable.

\section{Consent for publication}

Not applicable.

\section{Copyright}

(c) The Author(s) 2021.

\section{REFERENCES}

1. Podolsky D, Novitsky Y. Robotic inguinal hernia repair. Surg Clin North Am 2020;100:409-15. DOI PubMed

2. McCormack K, Wake B, Perez J, et al. Laparoscopic surgery for inguinal hernia repair: systematic review of effectiveness and economic evaluation. Health Technol Assess 2005;9:1-203, iii-iv. DOI PubMed

3. Cavazzola LT, Rosen, M. Laparoscopic versus open inguinal hernia repair. Surg Clin North Am 2013;93:1269-79. DOI PubMed

4. Claus C, Furtado M, Malcher F, Cavazzola LT, Felix E. Ten golden rules for a safe MIS inguinal hernia repair using a new anatomical concept as a guide. Surg Endosc 2020;34:1458-64. DOI PubMed

5. Group. International guidelines for groin hernia management. Hernia 2018;22:1-165. DOI PubMed PMC

6. Kudsi OY, Bou-Ayash N, Gokcal F. Robotic transabdominal preperitoneal repair of complex inguinal hernias. Int J Abdom Wall Hernia Surg 2021;4:1-6. DOI

7. Dominguez JE, Ramos MG, Seetharamaiah R, Donkor C, Rabaza J, Gonzalez A. Feasibility of robotic inguinal hernia repair, a singleinstitution experience. Surg Endosc 2016;30:4042-8. DOI PubMed

8. Tam V, Rogers DE, Al-Abbas A, et al. Robotic inguinal hernia repair: a large health system's experience with the first 300 cases and review of the literature. J Surg Res 2019;235:98-104. DOI PubMed

9. Aiolfi A, Cavalli M, Micheletto G, et al. Primary inguinal hernia: systematic review and Bayesian network meta-analysis comparing open, laparoscopic transabdominal preperitoneal, totally extraperitoneal, and robotic preperitoneal repair. Hernia 2019;23:473-84. DOI PubMed

10. Pokala B, Armijo PR, Flores L, Hennings D, Oleynikov D. Minimally invasive inguinal hernia repair is superior to open: a national database review. Hernia 2019;23:593-9. DOI PubMed

11. Prabhu AS, Carbonell A, Hope W, et al. Robotic inguinal vs transabdominal laparoscopic inguinal hernia repair: the RIVAL randomized clinical trial. JAMA Surg 2020;155:380-7. DOI PubMed PMC 
12. Strasberg SM, Hertl M, Soper NJ. An analysis of the problem of biliary injury during laparoscopic cholecystectomy. J Am Coll Surg 1995;180:101-25. PubMed

13. Berci G, Hunter J, Morgenstern L, et al. Laparoscopic cholecystectomy: first, do no harm; second, take care of bile duct stones. Surg Endosc 2013;27:1051-4. DOI PubMed

14. Daes J, Felix E. Critical view of the myopectineal orifice. Ann Surg 2017;266:e1-2. DOI PubMed

15. Furtado M, Claus CMP, Cavazzola LT, Malcher F, Bakonyi-Neto A, Saad-Hossne R. Systemization of laparoscopic inguinal hernia repair (TAPP) based on a new anatomical concept: inverted y and five triangles. Arq Bras Cir Dig 2019;32:e1426. DOI PubMed PMC

16. Alder R, Zetner D, Rosenberg J. Incidence of inguinal hernia after radical prostatectomy: a systematic review and meta-analysis. $J$ Urol 2020;203:265-74. DOI PubMed

17. Regan TC, Mordkin RM, Constantinople NL, Spence IJ, Dejter SW. Incidence of inguinal hernias following radical retropubic prostatectomy. Urology 1996;47:536-7. DOI PubMed

18. Fischer E, Wantz GE. Radical retropubic prostatectomy and groin hernia-cause and effect? Hernia 1997;1:67-70. DOI

19. Lodding P, Bergdahl C, Nyberg M, Pileblad E, Stranne J, Hugosson J. Inguinal hernia after radical retropubic prostatectomy for prostate cancer: a study of incidence and risk factors in comparison to no operation and lymphadenectomy. J Urol 2001;166:964-7. DOI PubMed

20. Stranne J, Johansson E, Nilsson A, et al. Inguinal hernia after radical prostatectomy for prostate cancer: results from a randomized setting and a nonrandomized setting. Eur Urol 2010;58:719-26. DOI PubMed

21. Bajpai RR, Razdan S, Sanchez-Gonzalez MA, Razdan S. Simultaneous robotic assisted laparoscopic prostatectomy (RALP) and inguinal herniorrhaphy (IHR): proof-of-concept analysis from a high-volume center. Hernia 2020;24:107-13. DOI PubMed

22. Rogers T, Parra-Davila E, Malcher F, et al. Robotic radical prostatectomy with concomitant repair of inguinal hernia: is it safe? $J$ Robot Surg 2018;12:325-30. DOI PubMed

23. Fukuta F, Hisasue S, Yanase M, et al. Preoperative computed tomography finding predicts for postoperative inguinal hernia: new perspective for radical prostatectomy-related inguinal hernia. Urology 2006;68:267-71. DOI PubMed

24. Page P, Smialkowski A, Morton J, Fenton-Lee D. Totally extraperitoneal inguinal hernia repair in patients previously having prostatectomy is feasible, safe, and effective. Surg Endosc 2013;27:4485-90. DOI PubMed

25. Dulucq J-L, Wintringer P, Mahajna A. Totally extraperitoneal (TEP) hernia repair after radical prostatectomy or previous lower abdominal surgery: is it safe? Surg Endosc 2006;20:473-6. DOI PubMed

26. Prassas D, Ntolia A, Brosa J, et al. Effect of previous lower abdominal surgery on outcomes following totally extraperitoneal (TEP) inguinal hernia repair. Surg Laparosc Endosc Percutan Tech 2019;29:267-70. DOI PubMed

27. Wauschkuhn CA, Schwarz J, Bittner R. Laparoscopic transperitoneal inguinal hernia repair (TAPP) after radical prostatectomy: is it safe? Surg Endosc 2009;23:973-7. DOI PubMed

28. Sakon M, Sekino Y, Okada M, Seki H, Munakata Y. Laparoscopic inguinal hernioplasty after robot-assisted laparoscopic radical prostatectomy. Hernia 2017;21:745-8. DOI PubMed

29. Angus A, DeMare A, Iacco A. Evaluating outcomes for robotic-assisted inguinal hernia repair in males with prior urologic surgery: a propensity-matched analysis from a national database. Surg Endosc 2020. DOI PubMed

30. Dewulf M, Aspeslagh L, Nachtergaele F, Pletinckx P, Muysoms F. Robotic-assisted laparoscopic inguinal hernia repair after previous transabdominal prostatectomy. Surg Endosc 2021. DOI PubMed

31. Sharma R, Fadaee N, Zarrinkhoo E, Towfigh S. Why we remove mesh. Hernia 2018;22:953-9. DOI PubMed

32. Kokotovic D, Bisgaard T, Helgstrand F. Long-term recurrence and complications associated with elective incisional hernia repair. JAMA 2016;316:1575-82. DOI PubMed

33. Bueno-Lledó J, Torregrosa-Gallud A, Carreño-Saénz O, et al. Partial versus complete removal of the infected mesh after abdominal wall hernia repair. Am J Surg 2017;214:47-52. DOI PubMed

34. Slooter GD, Zwaans WAR, Perquin CW, Roumen RMH, Scheltinga MRM. Laparoscopic mesh removal for otherwise intractable inguinal pain following endoscopic hernia repair is feasible, safe and may be effective in selected patients. Surg Endosc 2018;32:16139. DOI PubMed

35. Truong A, Al-Aufey BS, Towfigh S. Step-by-step guide to safe removal of pre-peritoneal inguinal mesh. Surg Endosc 2019;33:26805. DOI PubMed

36. Koning GG, Wetterslev J, van Laarhoven CJHM, Keus F. The totally extraperitoneal method versus Lichtenstein's technique for inguinal hernia repair: a systematic review with meta-analyses and trial sequential analyses of randomized clinical trials. PLoS One 2013;8:e52599. DOI PubMed PMC

37. Aasvang EK, Kehlet H. The effect of mesh removal and selective neurectomy on persistent postherniotomy pain. Ann Surg 2009;249:327-34. DOI PubMed

38. Morrell AC, Morrell ALG, Malcher F, Morrell AG, Morrell-Junior AC. Primary abandon-of-the-sac (PAS) technique: preliminary results of a novel minimally invasive approach for inguinoscrotal hernia repair. Arq Bras Cir Dig 2020;33:e1519. DOI PubMed PMC

39. Leibl BJ, Schmedt CG, Kraft K, Ulrich M, Bittner R. Scrotal hernias: a contraindication for an endoscopic procedure? Surg Endosc 2000;14:289-92. DOI PubMed

40. Bittner R, Arregui ME, Bisgaard T, et al. Guidelines for laparoscopic (TAPP) and endoscopic (TEP) treatment of inguinal hernia [International Endohernia Society (IEHS)]. Surg Endosc 2011;25:2773-843. DOI PubMed PMC

41. Yheulon CG, Maxwell DW, Balla FM, et al. Robotic-assisted laparoscopic repair of scrotal inguinal hernias. Surg Laparosc Endosc Percutan Tech 2018;28:188-92. DOI PubMed 
42. Siow SL, Mahendran HA, Hardin M, Chea CH, Nik Azim NA. Laparoscopic transabdominal approach and its modified technique for incarcerated scrotal hernias. Asian J Surg 2013;36:64-8. DOI PubMed 